\title{
Ion mobility spectrometry combined with multivariate statistical analysis: revealing the effects of a drug candidate for Alzheimer's disease on $A \beta 1-40$ peptide early assembly
}

\author{
Serena Lazzaro ${ }^{1} \cdot$ Nina Ogrinc $^{2} \cdot$ Lieke Lamont $^{2} \cdot$ Graziella Vecchio $^{3} \cdot$ Giuseppe Pappalardo $^{1} \cdot$ Ron M. A. Heeren ${ }^{2}$ (I)
}

Received: 6 April 2019 / Revised: 4 July 2019 / Accepted: 10 July 2019 / Published online: 12 August 2019

(C) The Author(s) 2019

\begin{abstract}
Inhibition of the initial stages of amyloid- $\beta$ peptide self-assembly is a key approach in drug development for Alzheimer's disease, in which soluble and highly neurotoxic low molecular weight oligomers are produced and aggregate in the brain over time. Here we report a high-throughput method based on ion mobility mass spectrometry and multivariate statistical analysis to rapidly select statistically significant early-stage species of amyloid- $\beta 1-40$ whose formation is inhibited by a candidate theranostic agent. Using this method, we have confirmed the inhibition of a Zn-porphyrin-peptide conjugate in the early self-assembly of A $\beta 40$ peptide. The MS/MS fragmentation patterns of the species detected in the samples containing the Zn-porphyrin-peptide conjugate suggested a porphyrin-catalyzed oxidation at Met-35(O) of A $\beta 40$. We introduce ion mobility MS combined with multivariate statistics as a systematic approach to perform data analytics in drug discovery/amyloid research that aims at the evaluation of the inhibitory effect on the $A \beta$ early assembly in vitro models at very low concentration levels of $A \beta$ peptides.
\end{abstract}

Keywords Alzheimer's disease (AD) · Amyloid $\beta$-peptide oligomers · Electrospray ionization-ion mobility-mass spectrometry $($ ESI-IM-MS) $\cdot$ Multivariate statistical analysis (MVA)

\section{Introduction}

Alzheimer's disease (AD) is a neurodegenerative disorder, generally associated with the accumulation of misfolded amyloid- $\beta(A \beta)$ peptides. The World Health Organization (WHO) and Alzheimer's Disease International estimate the number of people affected by $\mathrm{AD}$ alone will reach 81 million

Published in the topical collection Close-Up of Current Developments in Ion Mobility Spectrometry with guest editor Gérard Hopfgartner.

Electronic supplementary material The online version of this article (https://doi.org/10.1007/s00216-019-02030-7) contains supplementary material, which is available to authorized users.

Ron M. A. Heeren

r.heeren@maastrichtuniversity.nl

1 Institute of Biostructures and Bioimaging (IBB), National Research Council, Via Paolo Gaifami N.18, 95126 Catania, Italy

2 The Maastricht Multimodal Molecular Imaging institute M4IDivision of Imaging Mass Spectrometry, Maastricht University, Minderbroedersberg 4-6, 6211 LK Maastricht, The Netherlands

3 Department of Chemical Sciences, Catania University, Viale Andrea Doria, 6, 95125 Catania, Italy worldwide by 2040 , leading to a costly burden of disease [1]. Although substantial progress has been made in understanding $\mathrm{AD}$, the failure of symptomatic treatments for clinically diagnosed $\mathrm{AD}$ in phase III clinical trials indicates that our understanding of this disease is still incomplete. The search for an effective and safe drug therefore continues. Despite the continuous debate about the amyloid hypothesis, experimental and clinical evidence support the concept that proteolytic cleavage of APP [2, 3], leaving behind soluble peptides, primarily $A \beta 40$ and $A \beta 42$, is a very central factor to the development of AD. Interestingly, $A \beta 40$ is ten times more prevalent in the brain than $A \beta 42$ but less fibrillogenic [4-9]. In addition, controversy still exists as to which of the two forms is toxic to neurons. While the $A \beta$ monomer form remains benign [10], evidence indicates that pre-fibrillar soluble assemblies of both $A \beta 40$ and $A \beta 42$ peptides are the actual initiators of $\mathrm{AD}$ pathogenesis causing neuronal dysfunction and memory impairment [11-13]. These peptides are low molecular weight oligomers (LMWs) and not, as expected, mature end-stage amyloid fibrils. Reducing the prevalence of LMWs, intermediates with suitable inhibitors of the earlystage aggregation of $A \beta$ peptides might decrease neuronal toxicity [14-21]. A valid therapeutic strategy proposes the 
use of short peptides, which recognize $A \beta$ 's aggregationprone amino acid sequences, as the key disruptors of $A \beta$ 's self-assembly. It is known that the penta-peptide KLVFF, which is homologous to the $A \beta(16-20)$ region, strongly interacts with the full-length $A \beta$ peptide to prevent fibril formation [22, 23]. In our previous work [24], we reported the design, synthesis, and anti-fibrillogenic activity of a novel peptide conjugate (Fig. 1). This conjugate consists of a fluorescent zinc-containing porphyrin macrocycle, which is linked through a GPG peptide spacer to the KLVFF sequence of $\mathrm{A} \beta$ peptides (Zn-Porph).

Matrix-assisted laser desorption ionization-time of flightmass spectrometry (MALDI-ToF-MS) experiments indicated that $\mathrm{Zn-Porph}$ interacts with monomeric $\mathrm{A} \beta 42$ in a 1:1 molar ratio [24]. Yet, Thioflavin-T (ThT) kinetics and circular dichroism (CD) data showed that $\mathrm{Zn}$-Porph prevented the conformational transition of $A \beta 42$ to a $\beta$-sheet structure. Based on these results, we hypothesize an interaction mechanism involving the zinc ion and the KLVFF peptide of the porphyrin-peptide conjugate as recognition sites of the histidine residues and hydrophobic region of $\mathrm{A} \beta 42$, respectively. In continuation of our studies, we would like to further elucidate whether the $\mathrm{Zn}$-Porph also inhibits the $\mathrm{A} \beta$ early assembly. Specifically, to survey the Zn-Porph's in vitro binding and inhibitory effects on LMWs of $A \beta 40$ peptide. In this regard, recent studies have shown that electrospray ionization ion mobility mass spectrometry (ESI-IM-MS) is a promising analytical tool to investigate the size and conformational distribution of the $A \beta$ early-stage LMWs in vitro models [25-36]. In respect to the screening of inhibitors [37], only a few IMMS publications have attempted to identify small inhibitors of the initial assembly of $A \beta 40$ at very low concentration levels [38-41]. In these studies, small molecules were added at different ratios to solutions of synthetic or recombinant $A \beta 40$ at concentrations ranging from 10 to $32 \mu \mathrm{M}$. Herein, we investigated the in vitro efficacy of the Zn-Porph as the inhibitor of the early-stage assembly of synthetic $A \beta 40$ at $5 \mu \mathrm{M}$ and $20 \mu \mathrm{M}$. We combined IM-MS with multivariate statistical analysis (MVA) [42] to compare the IM-MS profiles of multiple samples [43] and to reveal a subset of statistically significant early-stage species of $A \beta 40$ whose formation was inhibited in the presence of the Zn-Porph. From a chemometric standpoint, statistical feature selection involves discriminant techniques (supervised models). The main difference compared with the unsupervised models (PCA) is that supervised models use a priori knowledge about the class to which a specific sample belongs. Geometrically, this is the same as identifying regions in the hyperspace of the variables corresponding to the different classes [44]. Supervised models are designed to build an algorithm between a set of descriptive variables (e.g., drift time $\mathrm{m} / \mathrm{z}$ pairs with corresponding ion intensity value in the IM-MS spectra) and the membership to a defined class of samples [45]. As a modification of the PLS algorithm, in the OPLS-DA model, the systematic variations in $\mathrm{X}$ are separated into two parts: one linear and one orthogonal to Y. Hence, the OPLS-DA model comprises two blocks of model variations: (1) the Y-predictive block, which represents the inter-classes variation, and (2) the Y-orthogonal block which constitutes the intra-class variation [46, 47]. The latter augments classification performance in cases where the individual classes exhibit divergence in within-class variation. This facilitates the interpretation of the model variations. In another words, OPLS-DA is an excellent tool to find "What's the difference" between sample classes, such as between in vitro models not containing and containing a drug candidate. In case of 2-class models, indeed, the OPLS-DA Splot helps to quickly select reliable features (drift time_ $\mathrm{m} / \mathrm{z}$ pairs), which capture the bulk of the ion intensity variation between the control group (e.g., samples not containing the inhibitor) and treated group (e.g., samples containing the inhibitor). The S-plot combines the information from a traditional loading plot (PLS or OPLS) and the confidence limits column plot (plot XVariance, XVar) resulting in an easier filtering out of low confidence limit features. The plot visualizes variable according to their contribution to the inter-classes separation, based on the covariance parameter magnitude, $(\mathrm{p}[1])$,
Fig. 1 Zinc-porphyrin conjugated with the central hydrophobic motif (KLVFF) of the $A \beta$ peptide (abbr. Zn-Porph)

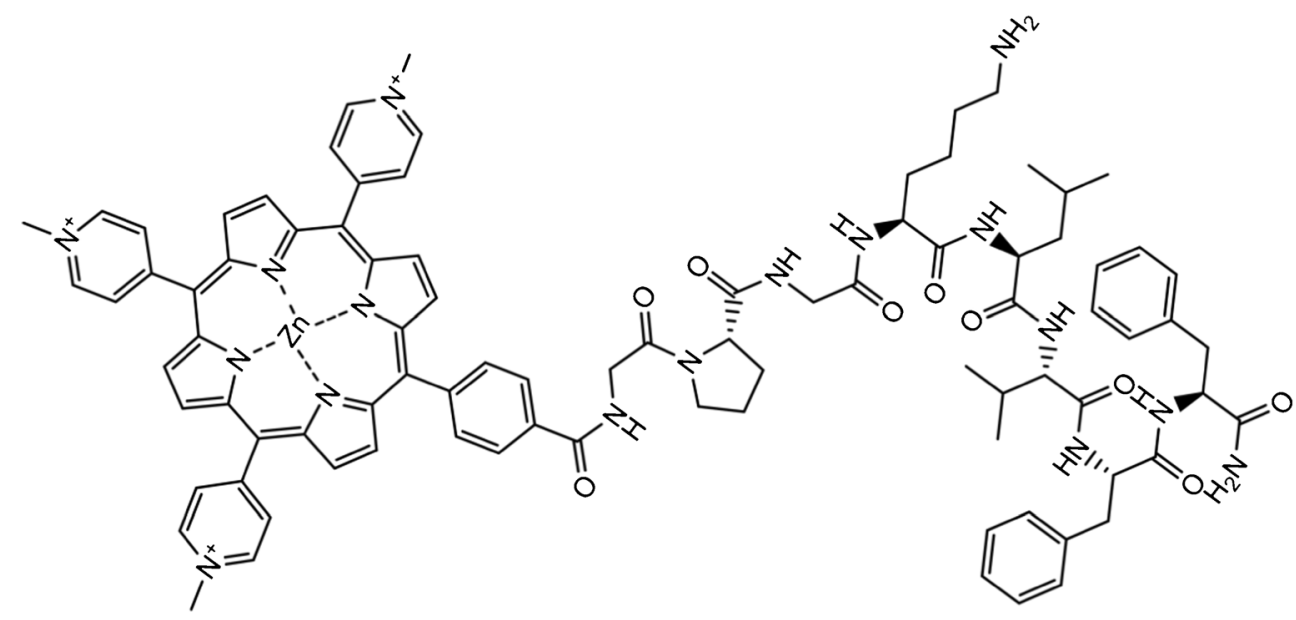


and to their reliability, based on the correlation parameter value, $(p(\operatorname{corr})[1])$. Both of these two parameters have a theoretical minimum of -1 and maximum of +1 . The selection of meaningful discriminative features needs, therefore, a combination of variable contribution (covariance, $\mathrm{p}[1]$ ) and variable confidence (correlation, $\mathrm{p}$ (corr)[1]) values, which is the purpose of the S-plot. The selected features can be further ranked by the variable of importance (VIP) plot [48]. The plot ranks the overall contribution of each variable to the model taking into account both $\mathrm{p}$ (corr)[1] and $\mathrm{p}[1]$ values. The variables with VIP value greaten than 1.0 can be selected as top "reliable ions with highest discriminatory capacity." In this study, a stringent threshold confidence interval was employed to select, among all the A $\beta 40$ early-stage species detected in sample classes not containing the inhibitor, the meaningful ATD peaks (with low intra-class ion intensity variability) whose intensity was significantly affected by the inhibitor in the sample classes containing ZnPorph.

\section{Material and methods}

\section{Sample preparation}

Samples were prepared from independent solutions of synthetic A $\beta 40$ peptide (purity $>95 \%$ ) purchased from GenScript. Eight units of $1.0 \mathrm{mg}$ of solid A $\beta 40$ were dissolved in pre-chilled 1,1,1,3,3,3-hexafluoro-2-propanol (HFIP) (Merck) to obtain a peptide concentration of $0.5 \mathrm{mM}$. The A $\beta 40$ solution was sonicated for $5 \mathrm{~min}$ at room temperature (RT), the tube was chilled on ice for $1 \mathrm{~min}$. The A $\beta 40$ solution was split into aliquots in siliconized tubes. From each aliquot, the HFIP was removed under the fume hood overnight and all traces evaporated using nitrogen. The day before the MS analysis, HFIP-treated A $\beta 40$ films were redissolved in dimethyl sulfoxide (DMSO, max $0.025 \%$ water, Merck). Each solution was sonicated for $5 \mathrm{~min}$ and subsequently incubated for $24 \mathrm{~h}$ at $25^{\circ} \mathrm{C}$. Prior to MS analysis, the solutions were diluted into $10 \mathrm{mM}$ ammonium acetate buffer (CH3COONH4, Aldrich), pH 6.9 (in which DMSO constitutes the $1 \% \mathrm{v} / \mathrm{v}$ of the final volume) to a final peptide concentration of 5 and $20 \mu \mathrm{M}$. All samples were subsequently centrifuged at $13,000 \mathrm{~g}$ for $10 \mathrm{~min}$ at $4{ }^{\circ} \mathrm{C}$. The supernatant solution was stored on ice for $5 \mathrm{~min}$ before injection. Another set of samples at $20 \mu \mathrm{M}$ was also incubated at $37^{\circ} \mathrm{C}$ for $2 \mathrm{~h}$ before storing them on ice prior to ESI-IM-MS analysis. ZnPorph (previously dissolved in CH3COONH4, $10 \mathrm{mM}$, $\mathrm{pH}$ 6.9) was added to monomeric $\mathrm{A} \beta 40$ in DMSO (as prepared above) in a 1:1 A $\beta 40: \mathrm{Zn}$-Porph molar ratio to study the effect on $A \beta 40$ assembly. Summarizing, three sample sets were investigated: at $5 \mu \mathrm{M}, 20 \mu \mathrm{M}$, and at $20 \mu \mathrm{M}$ incubated at $37{ }^{\circ} \mathrm{C}$ for $2 \mathrm{~h}$ prior to injection. The 16 samples of each sample set were grouped into 2 sample classes identified as
"A $\beta 40 "$ (eight samples) and "A $\beta 40$ plus Porph" (eight samples) to compare the ESI-IM-MS profiles of LMWs of A $\beta 40$ peptide in the presence and absence of equimolar amounts of Zn-Porph. A $\beta 40$ peptide solutions at $100 \mu \mathrm{M}$ were used to optimize the IM-MS settings in both resolution and sensitivity mode.

\section{MS method and instrumentation}

Direct infusion experiments were performed on a Synapt G2Si instrument (Waters Corp., Milford, MA). Measurements were performed at a $7 \mu \mathrm{L} / \mathrm{min}$ injection flow rate for $5 \mathrm{~min}$. Data were acquired in full scan mode using a mass range of $m / z, 800-3000$ at $1 \mathrm{scan} / \mathrm{sec}$. ESI was operated in the positive ion mode with a capillary voltage of $2.8 \mathrm{kV}$ and sample cone voltage of $38 \mathrm{~V}$. The source and desolvation temperatures were set at 80 and $40{ }^{\circ} \mathrm{C}$, respectively. Nitrogen was used as a cone gas with the flow rate of $38 \mathrm{~L} / \mathrm{h}$ and as desolvation gas with a flow rate of $650 \mathrm{~L} / \mathrm{h}$. The mobility T-wave cell was operated at a pressure of 3.19 mbar of nitrogen, with a wave velocity of $650 \mathrm{~m} / \mathrm{s}$ and amplitude of $39 \mathrm{~V}$. MS/MS spectra were acquired by CID fragmentation in the TRAP cell using collision energy of $70 \mathrm{~V}$ after precursor ion selection at LM resolution 6.5. Peak assignments were performed using their ${ }^{13} \mathrm{C}$ isotope distributions of the species separated in the IM dimension with the MS operating in resolution mode.

\section{Data processing and multivariate statistical analysis}

Data acquisition was carried out with MassLynx (V4.1) and DriftScope (V2.8) software. The total arrival time distribution (ATD) files classified as "A $\beta 40 "$ and "A $\beta 40$ plus Porph" were thus exported from DriftScope (V2.8) to Progenesis QI (64-bit, Nonlinear Dynamics). The Progenesis QI data analysis software is a small molecule discovery tool predominantly used to identify the significantly changing compounds in your dataset. In this particular case, the software was used for drift time alignment, peak picking, and normalization using total ion intensity. We obtained three data matrices, one for each of the investigated data set. Multiple features with same drift time and different $\mathrm{m} / \mathrm{z}$ may belong to the same compound due to the fragmentation, adduct formation, or clustering. The three data matrices were then exported from Progenesis QI to the statistical package EZinfo (V3.0.1.0, Umetrics). This was used to build 2-class orthogonal projection to latent structure-discriminant (OPLS-DA) models and S-plots for each sample set under investigation. Protein Prospector V5.22.1 (UCSF Mass Spectrometry Facility) and Fragment Ion Calculator (ISB Data Access Server) were used to analyze the MS/MS fragmentation ions from peptides. 


\section{Results}

\section{ESI-IM-MS analysis revealed that $A \beta 40$ predominantly oligomerizes through dimers and trimers}

In agreement with previously reported data $[25,38,39]$, the ESI-IM-MS analysis (Fig. 2) reveals that in the range 5$20 \mu \mathrm{M}$, the initially monomeric $\mathrm{A} \beta 40(\mathrm{M})$ oligomerizes predominantly through dimers (D) and trimers (TRI), the latter detectable with a signal-to-noise ratio lower than three $(\mathrm{S} / N<3)$. Peak assignments were performed as described in the Electronic Supplementary Material (ESM). As a result, the signal with a monoisotopic (mon) $\mathrm{m} / \mathrm{z}$ at 1082.79 was assigned to $[\mathrm{M}+4 \mathrm{H}]^{4+}$; the signal at 1443.39 (mon) to $[\mathrm{M}+$ $3 \mathrm{H}]^{3+}$; the three signals with the same (mon) $\mathrm{m} / z$ at 2164.58 were assigned to the $[\mathrm{M}+2 \mathrm{H}]^{2+},[\mathrm{D}+4 \mathrm{H}]^{4+}$, and $[\mathrm{TRI}+6 \mathrm{H}]^{6+}$, respectively; the signal at average $\mathrm{m} / \mathrm{z} 2598.92$ was identified as $[\mathrm{TRI}+5 \mathrm{H}]^{5+}$; the signal at average $\mathrm{m} / \mathrm{z} 2887.58$ as [D+ $3 \mathrm{H}]^{3+}$. The two signals with the same (mon) $\mathrm{m} / \mathrm{z}$ at 1731.87 but different mobilities (dt) were attributed to the compact and extended forms of the $[\mathrm{D}+5 \mathrm{H}]^{5+}$.
Upon the addition of the inhibitor (A $\beta 40: \mathrm{Zn}$-Porph, 1:1), the IM-MS of the "A $\beta 40$ plus Porph" sample sets revealed the detection of four new signals (Fig. 3) with monoisotopic (mon) $\mathrm{m} / \mathrm{z}$ at $1086.79,1448.72,1735.08$, and at 2172.63 , respectively. All of these peaks were associated to the corresponding charge state (see ESM Fig. S3). Furthermore, the signals of the $A \beta 40$ species previously detected in the "A $\beta 40$ " sample sets (Fig. 2) were below the detection limit or reduced. Moreover, no other ATD peaks with $\mathrm{S} / N>3$ and the same isotopic envelope of the two major $[\mathrm{D}+5 \mathrm{H}]^{5+}$ conformations were detected at drift times close to their drift times of the two major conformations.

\section{Identification of the new detected species}

MS/MS experiments were performed to identify the four new species shown in Fig. 3. We first investigated the fragmentation pattern (see ESM Fig. S4) of the predominant monomeric $\mathrm{M}^{3+}$ species of $\mathrm{A} \beta 40$ with (mon) $\mathrm{m} / \mathrm{z}$ at 1443.39 detected in "A $\beta 40$ " sample sets (Fig. 2). We mostly observed doubly and triply charged $b$-type ions covering the residues 11-39. MS/
Fig. $2 \mathrm{~A} \beta$ monomers in rapid equilibrium with low-order $\mathrm{A} \beta$ oligomers. At the top a 2D DriftScope IM-MS plot shows IM drift time versus $m / z$ versus intensity. The signal amplitude is color-coded, increasing from purple (low intensity) to bright yellow (high intensity). The plot shows the $A \beta 40$ species detected 5 min after diluting monomeric A $\beta 40$ to the final peptide concentration of $20 \mu \mathrm{M}$. The peak apexes have been accentuated by dots and annotated as monomers, dimers, and trimers of $\mathrm{A} \beta 40$ marked with $\mathrm{M}, \mathrm{D}$, and TRI with their charge (protonation) states. The peaks assigned to the $\mathrm{M}^{4+}$, $\mathrm{M}^{3+}, \mathrm{D}^{5+}, \mathrm{M}^{2+}, \mathrm{D}^{4+}$, and $\mathrm{TRI}^{+6}$ are labeled with the corresponding experimental monoisotopic $\mathrm{m} / \mathrm{z}$ (in parenthesis). The peaks assigned as $\mathrm{TRI}^{5+}$ and as $\mathrm{D}^{3+}$ are labeled with the experimental average $m / z$ (in parenthesis). At the bottom $\mathbf{b}$ ESI-MS spectrum of $20 \mu \mathrm{M} A \beta 40$. In red, the species detected with a $\mathrm{S} / N<3$. Satellite peaks observed correspond to alkali metal adduct commonly observed in ESI-MS
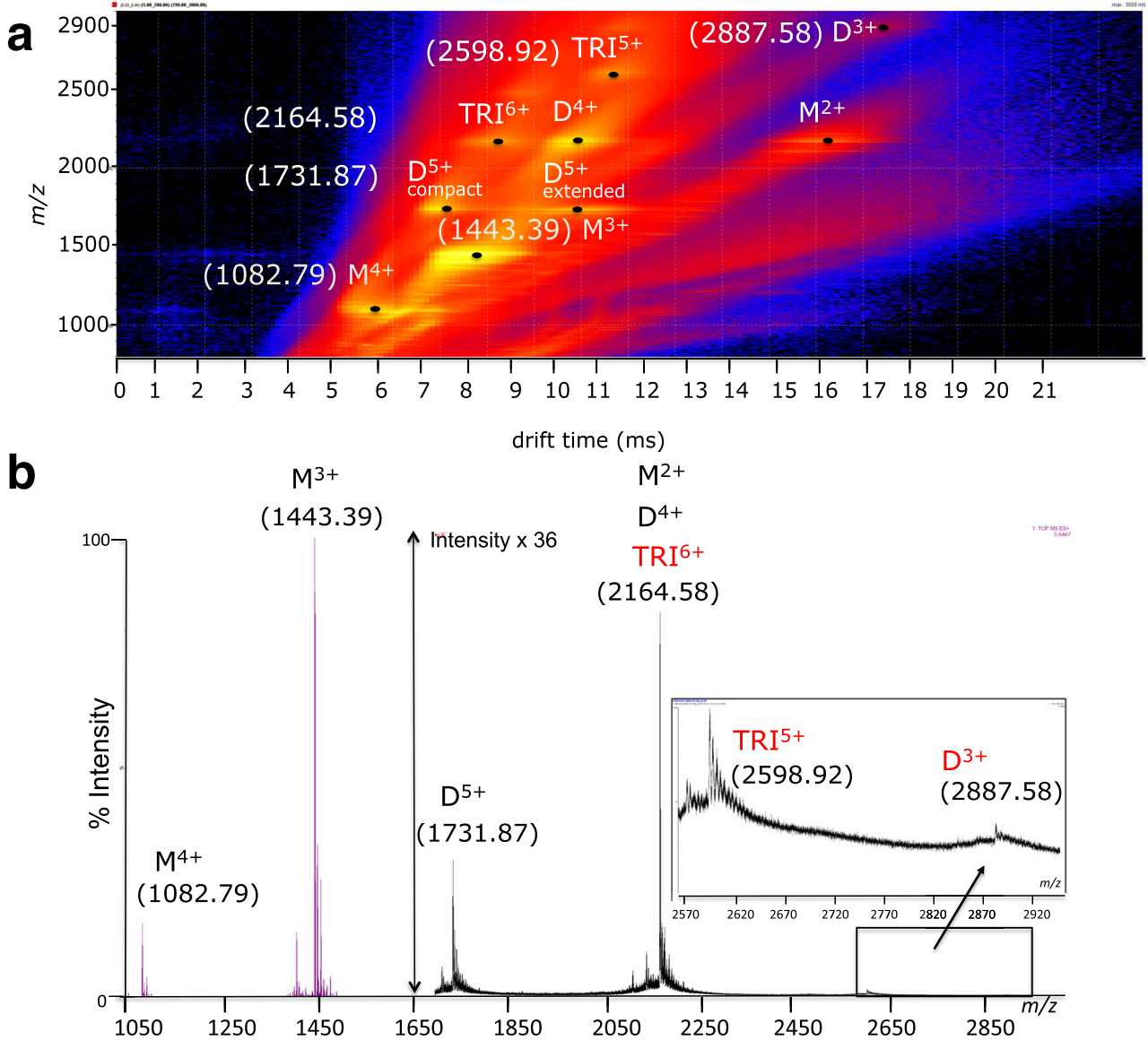


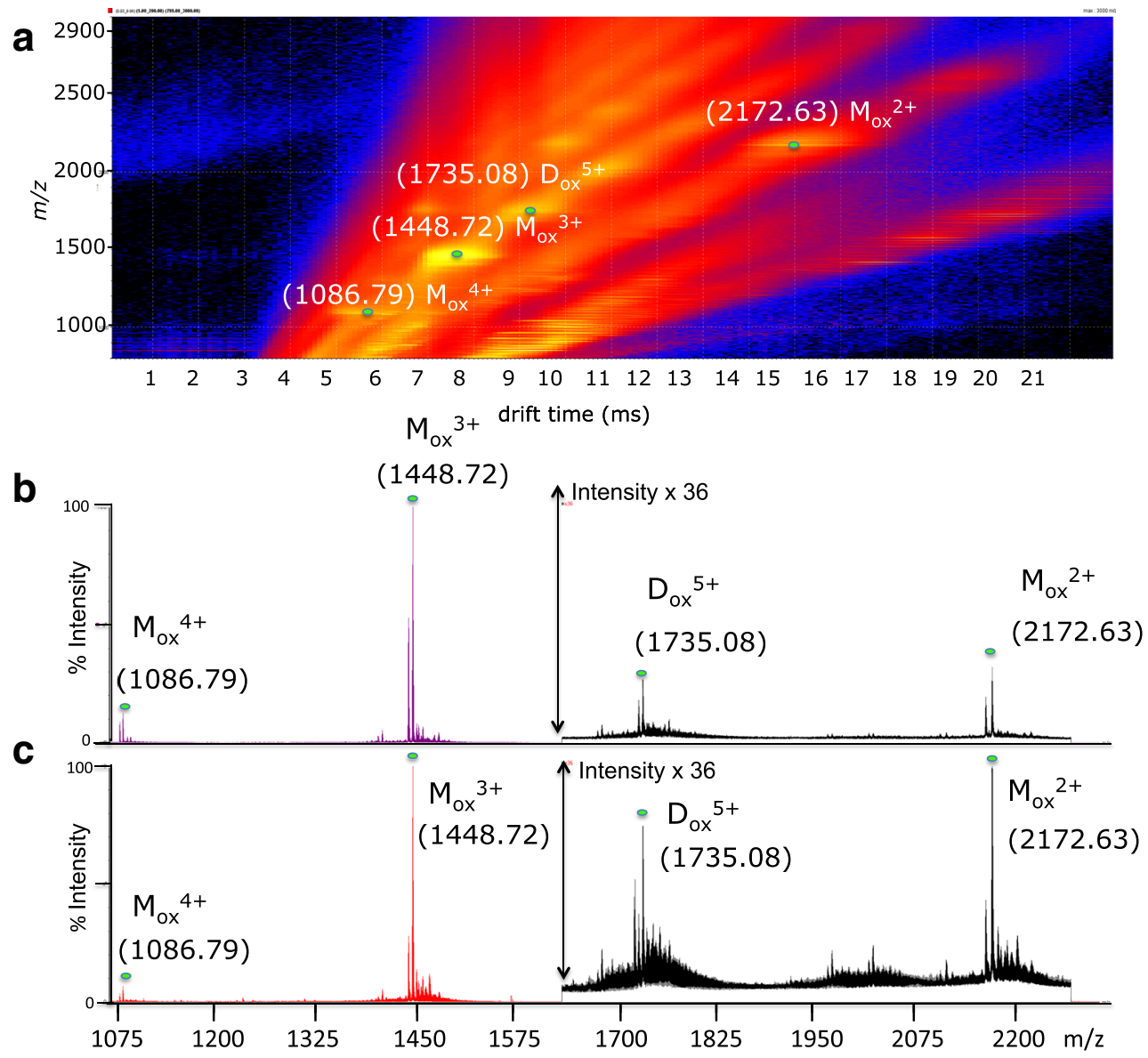

Fig. 3 IM-MS of "A $\beta 40$ plus Porph" sample sets (A $\beta 40: Z n-P o r p h, 1: 1)$ revealed the detection of new four signals. a 2D DriftScope IM-MS plots of the "A $\beta 40$ plus Porph" sample at $20 \mu \mathrm{M}$. Peak apexes have been accentuated by dots denoting the new detected species. Numbers in parenthesis above peaks denote their experimental monoisotopic $\mathrm{m} / \mathrm{z}$, with the positive charge state of the ions given as a superscript. The species with $\mathrm{m} / \mathrm{z}$ at 1448.72 , at 2173.63 , and at 1735.08 are also labeled with identity tag assigned following the considerations described in the following paragraph. The species at 1448.72 and at 2173.63 were assigned to

the protonated $\mathrm{A} \beta 40$ oxidized monomer, triply $\left(\mathrm{Mox}^{3+}\right)$, and doubly $\left(\mathrm{Mox}^{2+}\right)$ charged, respectively, while the species with $\mathrm{m} / \mathrm{z}$ at 1735.08 was identified as the quintuply protonated dimer of $A \beta 40$ consisting of one unit of oxidized $A \beta 40$ and another of unmodified $A \beta 40\left(\operatorname{Dox}^{5+}\right)$. b ESI-MS spectrum of an "A $\beta 40$ plus Porph" sample at $5 \mu \mathrm{M}$. $\mathbf{c}$ ESI-MS spectrum of an "A $\beta 40$ plus Porph" sample at $20 \mu \mathrm{M}$. Satellite peaks observed correspond to alkali metal adducts commonly observed in ESI-MS

MS fragmentation patterns were then predicted with the use of MS/MS database search programs (or and compared with those detected in the MS/MS spectrum of the $\mathrm{M}^{3+}$ (see ESM Table S1). The MS/MS pattern of the $\mathrm{M}^{3+}$ of $\mathrm{A} \beta 40$ detected in the "A $\beta 40$ " sample sets was compared with the MS/MS patterns of the new species with $m / z$ at $1086.79(+4), 1448.72(+$ 3), $1735.08(+5)$, and at $2172.63(+2)$ observed in the "A $\beta 40$ plus Porph" sample sets. Within the $\mathrm{m} / \mathrm{z}$ range $200-1250$, the MS/MS spectra of these species were the same as the MS/MS spectrum of the $\mathrm{M}^{3+}$ at $m / z$ 1443.39. In contrast, the $\mathrm{m} / \mathrm{z}$ range $1250-1420$ indicated that the new detected species resulted from a partial or a total methionine oxidation at position 35 (Met-35(O)). Starting from the residue at the position 35, the fragments $b_{35}{ }^{3+}, b_{36}{ }^{3+}, b_{37}{ }^{3+}, b_{38}{ }^{3+}, b_{39}{ }^{3+}$ previously detected for $\mathrm{M}^{3+}$ were shifted by 16.00 mass units (see ESM Fig. S5). This proves that the signals with (mon) $\mathrm{m} / \mathrm{z}$ at 1448.72 and at 2173.63 correspond to the monomer triply- $[\mathrm{A} \beta 40$ Met-
$\left.35(\mathrm{O})^{+} 3 \mathrm{H}\right]^{3+}$ - and doubly $[\mathrm{A} \beta 40 \mathrm{Met}-35(\mathrm{O})+2 \mathrm{H}]^{2+}$ charged ions, respectively. The detection of $b$-fragments of both oxidized and not oxidized $A \beta 40$ at the position 35-39 strongly suggests that the species at $m / z, 1735.08$ is the dimer $(+5)$ $[(\mathrm{A} \beta 40)(\mathrm{A} \beta 40 \mathrm{Met}-35(\mathrm{O}))+5 \mathrm{H}]^{5+}$ — consisting of one unit of $\mathrm{A} \beta 40$ Met-35(O) and another of unmodified A $\beta 40$ (see ESM Tables S2 and S3). The MS/MS spectrum of the species with $\mathrm{m} / \mathrm{z}$ at $1086.79(+4)$ was not covered by the $\mathrm{m} / \mathrm{z}$ informative range 1250-1420; however, the comparison of the experimental versus theoretical value indicates it corresponds to the monomer quadruply charged, $[\mathrm{A} \beta 40 \mathrm{Met}-35(\mathrm{O})+4 \mathrm{H}]^{4+}(\mathrm{see}$ ESM Table S2).

\section{Multivariate analysis}

The effect of Zn-Porph on the early assembly of $A \beta 40$ was studied using MVA [42, 43]. Each IM-MS run was imported 
into the Progenesis QI software as an ion intensity map including $\mathrm{m} / \mathrm{z}$ and drift times. The software was used for IM-MS data pre-processing, specifically for drift time alignment, peak picking (see ESM Fig. S6), and normalization. Data matrices were then exported from Progenesis QI to the statistical package EZinfo. The MVA revealed significant features (dt $\_m / z$ pairs) in the "A $\beta 40$ " class whose signal intensity was reduced in the "A $\beta 40$ plus Porph. 2-class OPLS-DA models [46], built on the entire ATDs, were constructed for each dataset to compare the peptide profiles detected for the " $A \beta 40$ " sample class to those detected for the "A $\beta 40$ plus Porph" class. Pareto scaling was used for the model construction. All OPLS-DA models had high value (0.99) of the goodness-of-fit parameter R2Y (cum). R2Y (cum) indicates how well the model fits data, as total sum of variation in $\mathrm{Y}$ explained by the model. S-plots of 2-class OPLS-DA models were constructed for each dataset. High discriminatory dt_ $m / z$ pairs of the "A $\beta 40$ " class, and hence, with likelihood of being potentialrobust quality markers (from now $d t+m / z$ marker pairs), were automatically selected on the basis of their intra-class intensity variability, measured by the correlation parameter, $p$ (corr)[1], as well as of their contribution to the inter-class separation, measured by the covariance parameter, $\mathrm{p}[1]$. $\mathrm{p}(\mathrm{corr})[1]>+0.9$ and $\mathrm{p}[1]>+0.05$ was the confidence interval adopted as threshold according to the selection procedure illustrated in Fig. 4.

The selected $d t \_m / z$ marker pairs of each sample set were finally ranked using the variable importance in projection (VIP) [48] plots (see ESM Fig. S7) to speed up the interpretation of the results. We observed that in all the sample sets under investigation, due to the low signal-to-noise $(\mathrm{S} / \mathrm{N})$ and the poor repeatability of the ion intensities $(\mathrm{p}(\mathrm{corr})[1]<+0.9$ ), the features corresponding to the $\mathrm{TRI}^{6+}, \mathrm{TRI}^{5+}$, and to the $\mathrm{D}^{3+}$ of $\mathrm{A} \beta 40$ were automatically excluded (VIP $<1)$. The feature corresponding to $\mathrm{M}^{2+}$ with a dt $\mathrm{m} / \mathrm{z}$ pair of 16.102164 .58 labeled as $\mathrm{M}^{2+}\left(16.10 \_2164.58\right)$ pair-was excluded only in the sample set at $5 \mu \mathrm{M}$, while it was selected as robust quality marker in the two sample sets at $20 \mu \mathrm{M}$. The features $\mathrm{M}^{3+}\left(7.83 \_1443.39\right), \mathrm{M}^{4+}\left(6.28 \_1082.79\right)$, and $\mathrm{D}^{4+}\left(10.36 \_2164.58\right),\left(10.80 \_1731.87\right)$, and (7.28_1731.87) corresponding to the extended and compact conformations of the $\mathrm{D}^{5+}$ were selected as $d t \mathrm{~m} / \mathrm{z}$ marker pairs to evaluate the inhibitory effect of Zn-Porph on their formation in the three sample sets investigated. By clicking on the VIP plot's bars (see ESM Fig. S8) corresponding to $d t \quad m / z$ marker pairs with a VIP value higher than one, ion intensity trend plots (XVar trend plots) were quickly generated to visualize the measured ion intensity value of each pair across all samples of the "A $\beta 40$ " and "A $\beta 40$ plus Porph" sample classes (see ESM Fig. S9). The average ion intensity of each $d t \_m / z$ marker pair in the two classes (see ESM Tables S4, S5, S6) was finally used to estimate the in vitro inhibition by the Zn-Porph on their formation. This was expressed as the reduction (in \%) of the average ion intensity of each $d t$ m $/ z$ marker pair measured in the "A $\beta 40$ plus Porph" class with respect to the average value measured in the "A $\beta 40$ " class (Fig. 5). Our findings revealed that in all data sets investigated, Zn-Porph alters the distribution of both monomeric and dimeric conformers of $A \beta 40$ over the timescale of our experiments. In particular, at $20 \mu \mathrm{M}$, the abundance of the conformer

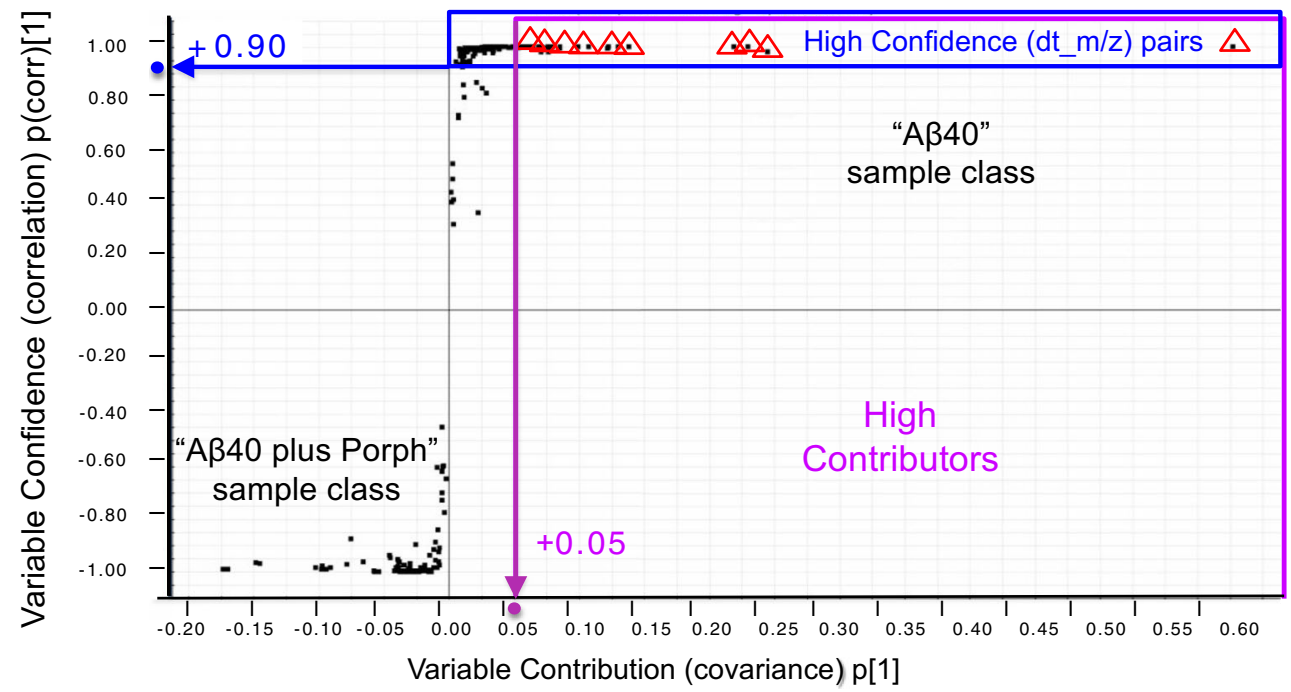

Fig. 4 Representative S-plot of OPLS-DA model separating peptide profiles of " $A \beta 40$ " class and of the "A $\beta 40$ plus Porph" class. The upper right quadrant of the S-plot shows those features which are elevated in "A $\beta 40$ " control group, while the lower left quadrant shows the pairs elevated in "A $\beta 40$ plus Porph" class. The farther along the $\mathrm{x}$-axis, the greater the contribution to the variance between the groups, while the farther the yaxis, the higher the reliability of the analytical result. The points are the features (drift time $\mathrm{m} / \mathrm{z}$ pairs). $d t \mathrm{~m} / \mathrm{z}$ marker pairs are selected based on their intra-class intensity variability, measured by the correlation parameter, $\mathrm{p}$ (corr)[1], as well as based on their contribution to the inter-class separation measured by the covariance parameter, $p[1]$ shown in S-plot. $\mathrm{p}$ (corr) $[1]>+0.9$ and $\mathrm{p}[1]>+0.05$ was employed as the threshold confidence interval 

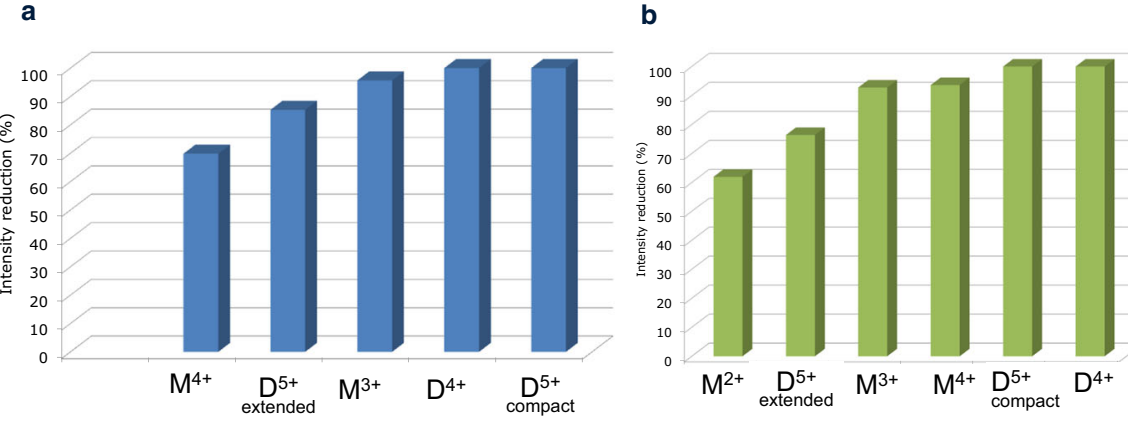

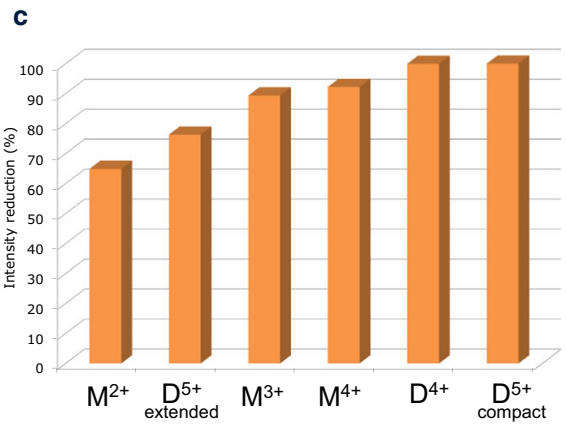

Fig. 5 The blue (a), the green (b), and the orange (c) histograms show the inhibitory effect of Zn-Porph (added to monomeric A 340 in DMSO in a 1:1 $\mathrm{M}$ ratio) on the formation of soluble monomeric and dimeric species of A $\beta 40$ selected as $d t \mathrm{~m} / \mathrm{z}$ marker pairs for the sample sets at $5 \mu \mathrm{M}$ (a), $20 \mu \mathrm{M}$ (b), and $20 \mu \mathrm{M}$ incubated before injection (c). The height of each bar represents the reduction (in \%) of the average ion intensity of each $d t$ $m / z$ marker pair measured in the "A $\beta 40$ plus Porph" sample class with respect to the average intensity measured in the "A $\beta 40$ " class. The species $\mathrm{M}^{4+}\left(6.28 \_1082.79\right), \mathrm{M}^{3+}\left(7.83 \_1443.39\right), \mathrm{D}^{5+}$ compact $(7.28$ 1731.87) conformation, $\mathrm{D}^{5+}$ extended (10.80_1731.87) conformation, and $\mathrm{D}^{4+}\left(10.36 \_2164.58\right)$ were all selected in the three sample sets as $d t$ m $/ z$ marker pairs to evaluate the inhibitory effect of Zn-Porph on their formation. In the sample set at $5 \mu \mathrm{M}(\mathbf{a})$, the feature $\mathrm{M}^{2+}\left(16.10 \_2164.58\right)$ was instead excluded due to its high intra-class intensity variability $(\mathrm{p}($ corr $)[1]<+0.9)$

of LMWs, especially as it has been reported as several different polymorphs exist [56, 57]. For the first time, we systematically analyzed the IM-MS profiles of LMWs of A $\beta 40$ peptide (A $\beta 40$ LMWs) in vitro models prepared from eight independent dissolutions of synthetic peptide, these are grouped as "A $\beta 40$ " sample class. Three sample sets were investigated, specifically, at $5 \mu \mathrm{M}, 20 \mu \mathrm{M}$, and at $20 \mu \mathrm{M}$ incubated at $37{ }^{\circ} \mathrm{C}$ for $2 \mathrm{~h}$ prior to injection. Using IM-MS-MVA, we investigated the inhibitory effect of the anti-fibrillogenic $\mathrm{Zn}$ Porph on A $\beta 40$ LMWs previously detected in the "A $\beta 40$ " sample class. Specifically, for each data set, MVA was used to remove the ATD peaks with high intra-class ion intensity variability in the "A $\beta 40$ " sample class as well as figured out the peaks that were significantly affected by the inhibitor in the "A $\beta 40$ plus Porph" class. Our study revealed that in the "A $\beta 40$ " sample class, the initially monomeric (M) A $\beta 40$ peptide oligomerizes predominantly through dimer (D) and trimer (TRI), the latter detectable with a $\mathrm{S} / N<3$. It is important to note that our results are consistent only with those studies that used the ${ }^{13} \mathrm{C}$ isotope distribution to assign peaks separated in the mobility dimension $[25,35]$. Of note, IM-MS data of the "A $\beta 40$ " sample class shows multiple monomer charge states, predominantly triply and quadruply charged. As previously reported by Young and co-workers [38] for the monomeric human islet amyloid polypeptide (hIAPP), and by Dadlez and co-workers [35] for the monomeric $\mathrm{A} \beta 40$, the distinct monomeric charge states may be indicative of a change in shape due to unfolding during the oligomerization process. Unfolded (extended) monomeric conformations expose more ionizable sites and thus give rise to higher charge states during ESI than the folded conformations of the same peptide. In IMMS ion intensity, quantification involves the integration of the area under the ATD peak, in the drift time spectra and mass spectra, and intensity is used as a direct measure of peptide abundance. Direct comparison of the corresponding peptide ical changes during the dissolution step $[54,55]$ lead to differences in the size and conformational distribution 
ATD peak area across different samples allows for the relative quantification of peptides. We initially observed that comparison of ATD peaks of the A $\beta 40$ species within the "A $\beta 40$ " sample class was complicated by ATD drifts. These can be due to a host of different factors, including sample stability, temperature and pressure fluctuations, deposit build-up, and heterogeneity and dynamic nature of $A \beta 40$ peptide and of its LMWs. The presence of interferences, e.g., other analytes with a similar ion mobility, and changing of peak positions dependent on environmental conditions, e.g., in the field operations, could strongly hamper proper analyte identification and quantification. For the purpose of this study, we focused on the major species detected in "A $\beta 40$ " sample class that give distinguishable peaks in the extracted ATDs (see ESM Fig. S2). In this respect, as previously reported [58], the structural heterogeneity and dynamic nature of the $\mathrm{D}^{+5}$ species is reflected in their ATD peak shape. ATD peaks that deviate slightly from Gaussian are consistent with multiple states, indicating the existence of multiple conformers rapidly interconverting on the ESI-IM-MS timescale [58]. We adopted an automatic alignment procedure, which compensates for small variation between runs in the IM drift times to combine and compare IM-MS profiles of A $\beta 40$ early species from different dissolutions without ATD peak distortions (see text in ESM). Using the automatic alignment tool, frames detected in all runs are automatically aligned with the base frames detected in a sample of the "A $\beta 40$ " sample class, selected as the reference run. Alignment is an essential 1-D IMMS data pre-processing step before MVA to achieve IM spectra that are reproducible between different samples and conditions [43]. It corrects for small variations in the temperature and pressure of the drift tube, resulting in changes in analyte drift time. This results in an increased precision of the ionabundance measurement of a peptide feature ( $\mathrm{dt}_{-} \mathrm{m} / \mathrm{z}$ pair) across multiple runs. Although the drift time alignment scores are dependent on the degree of overlap between features, and misalignment of conflicting features may still yield positive alignment scores, we used these scores as a qualitative measure of the IM-MS alignment, along with visual interpretation to determine alignment success. All 16 samples from the two sample classes were determined to have good alignment scores $(>80 \%)$. From these analyses, we conclude that drift time alignment scores should be at least $>80 \%$, and ideally $>$ $90 \%$, to minimize variation and improve precision in ionabundance measurements. This process is important because it facilitates consistent peak picking across multiple runs, enables appropriate normalization of data, reduces complications in assigning peptide identity, and allows the direct comparison of $A \beta 40$ LMW features across the "A $\beta 40$ " and "A $\beta 40$ plus Porph" sample classes (see ESM Fig. S6). This strategy is not only relevant to $A \beta 40$ assembly but may be useful to the studies focusing on the inhibition on $A \beta 42$ assembly and on other aggregation diseases such as Parkinson
(PD) or amyotrophic lateral sclerosis (ALS). Our findings revealed that in all data sets investigated, Zn-Porph alters the distribution of both monomeric and dimeric conformers of A $\beta 40$ over the timescale of our experiments, inhibiting their formation at the early stage of the aggregation pathway of $A \beta 40$. However, no complexes of $A \beta 40$ and $Z n$-Porph were observed. In this regard, it is important to note that the ESI process does not maintain hydrophobic interactions in the gasphase for very large molecular weight complexes [59], especially, when the ligand has a molecular weight higher than $800 \mathrm{Da}$, as in the case of Zn-Porph. The correspondence of MS/MS patterns predicted using de novo peptide sequencing algorithms to those ones of the species at $\mathrm{m} / \mathrm{z} 1448.72(+3)$, $1735.08(+5)$, and at $2172.63(+2)$ detected in the "A $\beta 40$ plus Porph" sample sets detected in the "A $\beta 40$ plus Porph" sample classes (see ESM Table S3) suggested a porphyrin-catalyzed oxidation in position $35(\mathrm{Met}-35(\mathrm{O}))$. This led to the detection of $\mathrm{A} \beta 40 \mathrm{Met}-35(\mathrm{O})$ monomer and mono-oxidized dimer; the latter consisting of one unit of $A \beta 40$ Met-35(O) and another of unmodified $A \beta 40-[(A \beta 40)(A \beta 40$ Met-35(O)]. The detection of one major ATD peak for the mono-oxidized dimer $\left(\right.$ Dox $^{5+}$ ) with $\mathrm{m} / \mathrm{z}$ (mon) at 1735.08 and with discernable isotopic distribution pattern (Fig. 3 and ESM Fig. S3) was an indication that the oxidation could possibly occur at Met-35 on one of the two $\mathrm{D}^{+5}$ conformers. A previous study [60] conducted on synthetic $A \beta 40$ by the sensitive electrospray ionization Fourier transform ion cyclotron resonance mass spectrometry (ESI-FTICR-MS) has shown that spectra acquired between 20 and 30 min immediately after dissolving the peptide contained less than $1 \%$ of $A \beta 40$ Met- $35(\mathrm{O})$. We, thus, exclude that the species detected in the "A $\beta 40$ plus Porph" sample classes could be a result of a spontaneous A $\beta 40$ oxidation over the timescale of our experiments. We also exclude that these could be oxidation artifacts of the ESI process [61] having used gentle ESI conditions (the capillary voltage and cone voltage were $2.8 \mathrm{kV}$ and $38 \mathrm{~V}$, respectively). Our results therefore strongly suggest a porphyrincatalyzed oxidation at the position 35 following the dilution of monomeric $A \beta 40$ peptide with acetate buffer containing an equimolar amount of $\mathrm{Zn}$-Porph. Such event is not unexpected since, as previously reported, porphyrin and its analogues have exhibited catalytic activity for highly selective monooxygenation reactions which proceed through singlet oxygen $\left({ }^{1} \mathrm{O}_{2}\right)$ generation [62-65]. The generated singlet oxygen readily reacted with the unoxidized $A \beta 40$ leading to the detection of the new detected species caused by the oxidation of Met35. It has been suggested that oxidation of Met-35(O) in $A \beta$ peptides significantly inhibits fiber formation. In vitro oxidation of $\mathrm{A} \beta$, by the physiological oxidant hydrogen peroxide $\left(\mathrm{H}_{2} \mathrm{O}_{2}\right)$, was monitored using Thioflavin- $\mathrm{T}$ (ThT), transmission electron microscopy (TEM) [66], circular dichroism (CD) [67], and solution NMR [68]. All of these studies suggested a disrupting effect of Met-35(O) on $\beta$-sheet formation. 
In particular, solution NMR findings indicate that Met-35(O) prevents aggregation by reducing both hydrophobic and electrostatic association and that the unoxidized and oxidized $\mathrm{A} \beta$ peptides may associate differently, through specific, sharp changes in structure during the initial stages of aggregation [69]. This raises the question of whether the porphyrincatalyzed oxidation positively affects the complex early assembly of $A \beta 40$ oligomers that ultimately lead to the fibers and plaques in the brain. ESI-FTICR-MS has shown that $\mathrm{A} \beta$ methionine in vitro oxidation induced by $\mathrm{H}_{2} \mathrm{O}_{2}$, which is a relatively mild oxidant present physiologically, inhibits trimer but not dimer formation in the early stage of $\mathrm{A} \beta 40$ aggregation [47]. In this study, $\mathrm{H}_{2} \mathrm{O}_{2}$ was added to a final concentration of $2.7 \%$ to synthetic $A \beta 40$ freshly dissolved in deionized water/acetic acid 99:1 (v/v), $\mathrm{pH} 3$ to a final peptide concentration of $4 \mu \mathrm{M}$. Our IM-MS-MVA combined study clearly provide us with the evidences that upon addition of the $\mathrm{Zn}$ Porph, the ATD features of the compact conformation $\mathrm{D}^{5+}$ and of $\mathrm{D}^{4+}$ were essentially eliminated, while the ATD peak of the extended conformation $\mathrm{D}^{+5}$ was significantly diminished. The latter by $85 \%$ in the sample set at $5 \mu \mathrm{M}$ and by $76 \%$ in the two sets at $20 \mu \mathrm{M}$. Our explanation is related to the possibility that Zn-Porph more likely forms a complex with the compact conformer being involved in an on-pathway fibrillation process, whereas the extended one could be involved also to the offpathway fibrillation leading to amorphous aggregates. Discordance between our findings and those from FTICRMS can be reconciled by taking into account the different oxidant involved in the process, $\mathrm{H}_{2} \mathrm{O}_{2}$ and aerobic oxygen, respectively. In this framework, a research group at the University of Tokyo recently found that catalytic oxygenation of $\mathrm{A} \beta$ peptides might be an effective approach to treat $\mathrm{AD}$ [69]. In this study, oxygenation of $A \beta$ by flavin catalyst attached to an $\mathrm{A} \beta$-binding peptide induced two favorable features for the treatment of AD. First, the pathological properties of native $A \beta$, aggregation potency and neurotoxicity, were markedly attenuated by oxygenation. Second, the oxygenated $A \beta$ inhibited the aggregation and cytotoxicity of native $A \beta$. Thus, flavin-catalyzed photo-oxidation of $A \beta$ not only decreases the concentration of aggregative and pathogenic natural $\mathrm{A} \beta$, but also increases the concentration of an aggregation inhibitor (oxygenated $A \beta$ ).

\section{Conclusions}

An attractive therapeutic approach for $\mathrm{AD}$ treatment is to remodel the initial stages of $A \beta$ assembly in a way that attenuates the neurotoxicity of the transient LMWs. Furthermore, the integration of therapeutic moieties and diagnostic ones in the same chemical scaffold a step forward towards personalized medicine for AD. ESI-IM-MS combined to MVA revealed that in all sample sets, the $\mathrm{Zn}$ -
Porph alters the distributions of both monomeric and dimeric conformers of $A \beta 40$ inhibiting their formation at the early stage of the $A \beta 40$ aggregation pathway. The correspondence of the MS/MS patterns predicted using MS/MS database search programs to those ones of the species detected in the samples of $A \beta 40$ containing $\mathrm{Zn}$ Porph suggested a porphyrin-catalyzed oxidation at Met$35(O)$ of $A \beta 40$. This led to the formation of $A \beta 40$ Met$35(\mathrm{O})$ monomer and mono-oxidized dimer consisting of one unit of $A \beta 40$ Met-35(O) and another of unmodified A $\beta 40$. Furthermore, our previously conducted MALDIToF-MS experiments indicated that Zn-Porph is able to aggregate, via formation of supramolecular adduct, with the monomeric $A \beta 42$. Thus, binding to and stabilizing A $\beta 40$ monomer, with concomitant catalyzed oxidation, could be the mechanism of the $\mathrm{A} \beta$ self-assembly inhibition by this candidate theranostic agent. The Zn-Porph investigated here could indeed potentially serve as invivo fluorescent ligand for visualization and identification of soluble LMWs of $A \beta$ in biological fluids, progression prediction, and differential diagnosis, to finally tailor personalized and precision dosages [70-74]. This remains the big challenge in AD drug discovery. Going forward, intrinsic porphyrin bio-compatibility and multimodality will keep new applications of this class of molecules at the forefront of theranostic research $[75,76]$. We here also introduced a novel data analytics approach in drug discovery/amyloid research. This systematic approach could be particularly suitable in amyloid research aiming at evaluating the inhibitory effect of a candidate $\mathrm{AD}$ drug on the early-assembly of $A \beta$ in vitro models at very low concentration levels of $A \beta$.

Acknowledgments We thank Rita Tosto at the Institute of Biostructures and Bioimaging (IBB)-CNR Catania for her contribution to the synthesis of the $\mathrm{Zn}$-Porph used in this work.

Funding information The work has been supported by the INCIPIT project (grant agreement no. 665403) co-funded by the Marie Skłodowska Curie Actions (Excellent Science) and the National Research Council (CNR) of Italy (S.L and G. P). CNR-HAS joint research project is also acknowledged for partial financial support. The Maastricht MultiModal Molecular Imaging institute (R.M.A.H., N.O. and L.L.) acknowledges financial support of the LINK program of the Dutch province of Limburg for this work. L.L. acknowledges financial support from Janssen Pharmaceutica.

\section{Compliance with ethical standards}

Conflict of interest The authors declare that they have no conflict of interest.

Open Access This article is distributed under the terms of the Creative Commons Attribution 4.0 International License (http:// creativecommons.org/licenses/by/4.0/), which permits unrestricted use, distribution, and reproduction in any medium, provided you give 
appropriate credit to the original author(s) and the source, provide a link to the Creative Commons license, and indicate if changes were made.

\section{References}

1. World Health Organization and Alzheimer's Disease International. Dementia: a public health priority. World Health Organization and Alzheimer's Disease International. Report 2012. https://www.alz. co.uk/WHO-dementia-report Accessed February 2018

2. Haass C, Schlossmacher MG, Hung AY, Vigo-Pelfrey C, Mellon A, Ostaszewski BL, et al. Amyloid $\beta$-peptide is produced by cultured cells during normal metabolism. Nature. 1992;359:322-5.

3. Takami M, Nagashima Y, Sano Y, Ishihara S, MorishimaKawashima M, Funamoto S, et al. $\gamma$-Secretase: successive tripeptide and tetrapeptide release from the transmembrane domain of $\beta$-carboxyl terminal fragment. J Neurosci. 2009;29:13042-52.

4. Jakob-Roetne R, Jacobsen H. Alzheimer's disease: from pathology to therapeutic approaches. Angew Chem Int Ed. 2009;48:3030-59.

5. Dahlgren KN, Manelli AM, Stine WB, Baker LK, Krafft GA, LaDu MJ. Oligomeric and fibrillar species of amyloid- $\beta$ peptides differentially affect neuronal viability. J Biol Chem. 2002;277:32046-53.

6. Lesné S, Koh MT, Kotilinek L, Kayed R, Glabe CG, Yang A, et al. A specific amyloid- $\beta$ protein assembly in the brain impairs memory. Nature. 2006;440:352-7.

7. Cheng IH, Scearce-Levie K, Legleiter J, Palop JJ, Gerstein H, BienLy N, et al. Accelerating amyloid- $\beta$ fibrillization reduces oligomer levels and functional deficits in Alzheimer disease mouse models. J Biol Chem. 2007;282:23818-28.

8. Mann DM, Iwatsubo T, Ihara Y, Cairns NJ, Lantos PL, Bogdanovic $\mathrm{N}$, et al. Predominant deposition of amyloid- $\beta 42(43)$ in plaques in cases of Alzheimer's disease and hereditary cerebral hemorrhage associated with mutations in the amyloid precursor protein gene. Am J Pathol. 1996;148:1257-66.

9. Billings LM, Oddo S, Green KN, McGaugh JL, LaFerla FM. Intraneuronal $A \beta$ causes the onset of early Alzheimer's diseaserelated cognitive deficits in transgenic mice. Neuron. 2005;45: 675-88.

10. Giuffrida ML, Caraci F, Pignataro B, Cataldo S, De Bona P, Bruno $\mathrm{V}$, et al. Beta-amyloid monomers are neuroprotective. J Neurosci. 2009;29:10582-7.

11. Sakono M, Zako T. Amyloid oligomers: formation and toxicity of Abeta oligomers. FEBS J. 2010;277:1348-58.

12. Klyubin I, Cullen WK, Hu NW, Rowan MJ. Alzheimer's disease $\mathrm{A} \beta$ assemblies mediating rapid disruption of synaptic plasticity and memory. Mol Brain BioMed Central. 2012;5:1-10.

13. Larson ME, Lesné SE. Soluble A $\beta$ oligomer production and toxicity. J Neurochem. 2012;120:125-39.

14. Walsh DM, Selkoe DJ. A $\beta$ oligomers - a decade of discovery. J Neurochem. 2007;101:1172-84.

15. Sadigh-Eteghad S, Sabermarouf B, Majdi A, Talebi M, Farhoudi M, Mahmoudi J. Amyloid-beta: a crucial factor in Alzheimer's disease. Review. Med Princ Pract. 2015;24:1-10.

16. Zheng X, Wu C, Liu D, Li H, Bitan G, Shea JE, et al. Mechanism of C-terminal fragments of amyloid -protein as a inhibitors: do Cterminal interactions play a key role in their inhibitory activity? J Phys Chem B. 2016;120:1615-23.

17. Zheng X, Liu D, Klaerner FG, Schrader T, Bitan G, Bowers MT. Amyloid beta-protein assembly: the effect of molecular tweezers CLR01 and CLR03. J Phys Chem B. 2015;119:4831-41.

18. Mason JM, Kokkoni N, Stott K, Doig AJ. Design strategies for antiamyloid agents. Curr Opin Struct Biol. 2003;13:526-32.
19. Bartolini M, Andrisano V. Strategies for the inhibition of protein aggregation in human diseases. Chembiochem. 2010;11:1018-35.

20. Liu T, Bitan G. Modulating self-assembly of amyloidogenic proteins as a therapeutic approach for neurodegenerative diseases: strategies and mechanisms. ChemMedChem. 2012;7:359-74.

21. Feng BY, Toyama BH, Wille H, Colby DW, Collins SR, May BCH, et al. Small-molecule aggregates inhibit amyloid polymerization. Nat Chem Biol. 2008;4:197-9.

22. Tjernberg LO, Näslund J, Lindqvist F, Johansson J, Karlström AR, Thyberg J, et al. Arrest of graphic-amyloid fibril formation by a pentapeptide ligand. J Biol Chem. 1996;271:8545-8.

23. Lowe TL, Strzelec A, Kiessling LL, Murphy RM. Structurefunction relationships for inhibitors of beta- amyloid toxicity containing the recognition sequence KLVFF. Biochemistry. 2001;40: 7882-9.

24. Villari V, Tosto R, Di Natale G, Sinopoli A, Tomasello MF, Lazzaro $\mathrm{S}$, et al. A metalloporphyrin-peptide conjugate as an effective inhibitor of amyloid- $\beta$ peptide fibrillation and cytotoxicity. Chem Select. 2017;2:9122-9.

25. Pujol-Pina R, Vilaprinyó-Pascual S, Mazzucato R, Arcella A, Vilaseca M, Orozco M, et al. SDS-PAGE analysis of A $\beta$ oligomers is disserving research into Alzheimer's disease: appealing for ESIIM-MS. Sci Rep. 2015;5:14809.

26. Ashcroft A. Mass spectrometry and amyloid problem-how far can we go in the gas phase? J Am Soc Mass Spectrom. 2010;21:108796.

27. Murray M, Bernstein S, Nyugen V, Condron M, Teplow D, Bowers M. Amyloid $\beta$ protein: $A \beta 40$ inhibits $A \beta 42$ oligomerization. J Am Chem Soc. 2009;131:6316-7.

28. Economou NJ, Giammona MJ, Do TD, Zheng X, Teplow DB, Buratto SK, et al. Amyloid $\beta$-protein assembly and Alzheimer's disease: dodecamers of $A \beta 42$, but not of $A \beta 40$, seed fibril formation. J Am Chem Soc. 2016;138:1772-5.

29. Radko SP, Khmeleva SA, Suprun EV, Kozin SA, Bodoev NV, Makarov AA, et al. Physico-chemical methods for studying amyloid- $\beta$ aggregation. Biomed Khim. 2015;9:258-74.

30. Sitkiewicz E, Kłoniecki M, Poznański J, Bal W, Dadlez M. Factors influencing compact-extended structure equilibrium in oligomers of A $\beta 1-40$ peptide - an ion mobility mass spectrometry study. J Mol Biol. 2014;426:2871-85.

31. Woods LA, Radford SE, Ashcroft AE. Advances in ion mobility spectrometry-mass spectrometry reveal key insights into amyloid assembly. Biochim Biophys Acta. 1834;2013:1257-68.

32. Gessel MM, Wu C, Li H, Bitan G, Shea JE, Bowers MT. A $\beta(39$ 42) modulates $A \beta$ oligomerization but not fibril formation. Biochemistry. 2012;51:108-17.

33. Bleiholder C, Dupuis NF, Wyttenbach T, Bowers MT. Ion mobility-mass spectrometry reveals a conformational conversion from random assembly to b-sheet in amyloid fibril formation. Nat Chem. 2011;3:172-7.

34. Bernstein SL, Dupuis NF, Lazo ND, Wyttenbach T, Condron MM, Bitan $\mathrm{G}$, et al. Amyloid- $\beta$ protein oligomerization and the importance of tetramers and dodecamers in the aetiology of Alzheimer's disease. Nat Chem. 2009;1:326-31.

35. Kloniecki M, Jablonowska A, Poznanski J, Langridge J, Hughes C, Campuzano I, et al. Ion mobility separation coupled with MS detects two structural states of Alzheimer's disease A $\beta$ 1-40 peptide oligomers. J Mol Biol. 2011;407:110-24.

36. Bleiholder C, Do TD, Wu C, Economou NJ, Bernstein SS, Buratto SK, et al. Ion mobility spectrometry reveals the mechanism of amyloid formation of $\mathrm{A} \beta(25-35)$ and its modulation by inhibitors at the molecular level: epigallocatechin gallate and scyllo-inositol. J Am Chem Soc. 2013;135:16926-37.

37. Hoffmann W, von Helden G, Pagel K. Ion mobility-mass spectrometry and orthogonal gas-phase techniques to study amyloid formation and inhibition. Curr Opin Struct Biol. 2017;46:7-15. 
38. Young LM, Saunder JC, Mahood RA, Revill CH, Foster RJ, Tu L, et al. Screening and classifying small molecule inhibitors of amyloid formation using ion mobility spectrometry-mass spectrometry. Nat Chem. 2015;7:73-81.

39. Young LM, Saunders JC, Mahood RA, Revill CH, Foster RJ, Ashcroft AE, et al. ESI-IMS-MS: a method for rapid analysis of protein aggregation and its inhibition by small molecules. Methods. 2016;95:62-9.

40. Soper MT, DeToma AS, Hyung S, Lim M, Ruotolo BT. Amyloidb-neuropeptide interactions assessed by ion mobility-mass spectrometry. Phys Chem Chem Phys. 2013;15:8952-61.

41. De Almeida NEC, Do TD, LaPointe NE, Tro M, Feinstein SC, Shea $\mathrm{JM}$, et al. 1,2,3,4,6-penta-O-galloyl- $\beta$-D-glucopyranose binds to the $\mathrm{N}$-terminal metal binding region to inhibit amyloid $\beta$-protein oligomer and fibril formation. Int J Mass Spectrom. 2017;420:24 34.

42. Engkilde K, Jacobsen S, Søndergaard I. Multivariate data analysis of proteome data. Methods Mol Biol. 2007;355:195-210.

43. Szymańska E, Davies ND, Buydens LMC. Chemometrics for ion mobility spectrometry data: recent advances and future prospects. Analyst. 2016;141:5689-708.

44. Marini F. Classification methods in chemometrics. Curr Anal Chem. 2010;6:72-9.

45. Berrueta LA, Alonso-Salces RM, Heberger K. Supervised pattern recognition in food analysis. J Chromatogr A. 2007;1158:196-214.

46. Trygg J, Wold S. Orthogonal projections to latent structures (OPLS). J Chemom. 2002;16:119-28.

47. Bylesjö M, Rantalainen M, Cloarec O, Nicholson JK, Holmes E, Trygg J. OPLS discriminant analysis: combining the strengths of PLS-DA and SIMCA classification. J Chemom. 2006;20:341-51.

48. Chen M, Cook KD. Oxidation artifacts in the electrospray mass spectrometry of a peptide. Anal Chem. 2007;79:2031-6.

49. McLean CA, Cherny RA, Fraser FW, Fuller SJ, Smith MJ, Vbeyreuther $\mathrm{K}$, et al. Soluble pool of $\mathrm{A} \beta$ amyloid as a determinant of severity of neurodegeneration in Alzheimer's disease. Ann. Neurol. 1999;46:860-6.

50. Seubert P, Vigo-Pelfrey C, Esch F, Lee M, Dovey H, Davis D, et al. Isolation and quantification of soluble Alzheimer's beta-peptide from biological fluids. Nature. 1992;359:325-7.

51. Lue LF, Kuo YM, Roher AE, Brachova L, Shen Y, Sue L, et al. Soluble amyloid $\beta$ peptide concentration as a predictor of synaptic change in Alzheimer's disease. Am J Pathol. 1999;155:853-62.

52. Harper JD, Lansbury PT. Models of amyloid seeding in Alzheimer's disease and scrapie: mechanistic truths and physiological consequences of the time-dependent solubility of amyloid proteins. Annu Rev Biochem. 1997;66:385-407.

53. Suvorina MY, Selivanova OM, Grigorashvili EI, Nikulin AD, Marchenkov VV, Surin AK, et al. Studies of polymorphism of amyloid- 42 peptide from different suppliers. J Alzheimers Dis. 2015;47:583-93.

54. Rahimi F, Bitan G. Methods for studying and structure-function relationships of non-fibrillar protein assemblies in Alzheimer's disease and related disorders. In: Lahiri DK, editor. Advances in Alzheimer's Research; 2014. p. 291-374.

55. Laurent S, Ejtehadi MR, Rezaei M, Kehoe PG, Mahmoudi M. Interdisciplinary challenges and promising theranostic effects of nanoscience in Alzheimer's disease. RSC Adv. 2012;2:5008-33.

56. Paravastu AK, Leapman RD, Yau WM, Tycko R. Molecular structural basis for polymorphism in Alzheimer's $\beta$-amyloid fibrils. Proc Natl Acad Sci U S A. 2008;105:18349-54.
57. Berryman JT, Radford SE, Harris SA. Systematic examination of polymorphism in amyloid fibrils by molecular-dynamics simulation. Biophys J. 2011;100:2234-42.

58. Young LM, Mahood RA, Saunders JC, Tu L, Raleigh DP, Radford $\mathrm{SE}$, et al. Insights into the consequences of co-polymerisation in the early stages of IAPP and A $\beta$ peptide assembly from mass spectrometry. Analyst. 2015;140:6990-9.

59. Loo JA. Studying noncovalent protein complexes by electrospray ionization mass spectrometry. Mass Spectrom Rev. 1997;16:1-23.

60. Palmblad M, Westlind-Danielsson A, Bergquist J. Oxidation of methionine 35 attenuates formation of amyloid $\beta$-peptide $1-40$ oligomers. J Biol Chem. 2002;277:19506-10.

61. Jeong HG, Cho MS. Design and properties of porphyrin-based singlet oxygen generator. Isr J Chem. 2016;56:110-8.

62. Barona-Castaño JC, Carmona-Vargas CC, Brocksom TJ, de Oliveira KT. Porphyrins as catalysts in scalable organic reactions. Molecules. 2016;21:310.

63. Twarowski AJ. Porphyrin-sensitized formation of a polymer-bound endoperoxide in the solid state. J Phys Chem. 1988;92:6580-4.

64. Chino M, Leone L, Zambrano G, Pirro F, D'Alonzo D, Firpo V, et al. Oxidation catalysis by iron and manganese porphyrins within enzyme-like cages. Biopolymers. 2018;109:e23107.

65. Gu M, Viles JH. Methionine oxidation reduces lag-times for amyloid-(1-40) fiber formation but generates highly fragmented fibers. Biochim Biophys Acta. 1864;2016:1260-9.

66. Watson AA, Fairlie DP, Craik DJ. Solution structure of methionineoxidized amyloid $\beta$-peptide (1-40). Does oxidation affect conformational switching? Biochemistry. 1998;37:12700-6.

67. Hou L, Shao H, Zhang Y, Li H, Menon NK, Neuhaus EB, et al. Solution NMR studies of the A beta(1-40) and A beta(1-42) peptides establish that the Met35 oxidation state affects the mechanism of amyloid formation. J Am Chem Soc. 2004;126:1992-2005.

68. Taniguchi A, Sasaki D, Shiohara A, Iwatsubo T, Tomita T, Sohma $\mathrm{Y}$, et al. Attenuation of the aggregation and neurotoxicity of amyloid- $\beta$ peptides by catalytic photooxygenation. Angew Chem Int Ed. 2014;53:1382-5.

69. Gotovac K, Hajnšek S, Pašić MB, Pivac N, Borovečki F. Personalized medicine in neurodegenerative diseases: how far away? Mol Diagn Ther. 2014;18:17-24.

70. Reitz C. Toward precision medicine in Alzheimer's disease. Transl Med. 2016;4:1-7.

71. Kosik KS. Personalized medicine for effective Alzheimer disease treatment. Jama Neurol. 2015;72:497-8.

72. Chen XS. Introducing theranostics journal. Theranostics. 2011;1:12.

73. Bolognesi ML, Gandini A, Prati F, Uliassi E. From companion diagnostics to theranostics: a new avenue for Alzheimer's disease? J Med Chem. 2016;59:7759-70.

74. Zhang Y, Lovell JF. Porphyrins as theranostic agents from prehistoric to modern times. Theranostics. 2012;2:905-15.

75. Josefsen LB, Boyle RW. Unique diagnostic and therapeutic roles of porphyrins and phthalocyanines in photodynamic therapy, imaging and theranostics. Theranostics. 2012;2:916-66.

76. Galindo-Prieto B, Eriksson L, Trygg J. Variable influence on projection (VIP) for OPLS models and its applicability in multivariate time series analysis. Chemom Intell Lab Syst. 2015;146:297-304.

Publisher's note Springer Nature remains neutral with regard to jurisdictional claims in published maps and institutional affiliations. 